\title{
Sales policy: arrangement and controlling
}

\author{
Alina Fatkullina ${ }^{1}$, and Yulia Beliaeva ${ }^{2 *}$ \\ ${ }^{1}$ Department of Economics and Organization in Agriculture, federal state budgetary educational \\ institution, higher education "St. Petersburg State Agrarian University" (St. Petersburg, Pushkin, \\ Russia) \\ ${ }^{2}$ Department of Foreign Languages and Speech Culture, federal state budgetary educational \\ institution, higher education "St. Petersburg State Agrarian University" (St. Petersburg, Pushkin, \\ Russia)
}

\begin{abstract}
The article is devoted to the study of the commodity policy, which directly plays a key role in the management of any company, as well as affects all aspects of its activities. It examines the directions and goals of the product policy, studies its components and principles, as well as methods of managing the company's product policy. The main idea is to reveal the essence of the product policy as an economically significant and effective tool for managing the company.
\end{abstract}

\section{Introduction}

It's all known that if earlier companies were not in need to think about the sale of products, this was done by the state, today every enterprise in a market economy, at its own risk, decides what it wants to produce and how to sell its goods and what funds will be used in this case. Every organization strives to conquer the market. All this encourages them to resort to various methods that promote the sale of products and services.

The sales system is the main link in the marketing system. The problem of sales is solved by manufacturers already at the stage of developing the company's policy, that is, the most effective system of sales channels is selected in relation to specific markets. Any product requires promotion on the market, which means the need for high-quality and unique advertising, various promotions. In addition, the company should have as wide network of retail sales or a network of intermediary companies as possible, unless it is engaged in very large and expensive production. Therefore, the relevance of this topic of the article is related to the fact that the organization and management of sales activities of the enterprise is one of the most important elements of the system of interaction between the firm and the consumer as subjects of economic relations.

Sales activity (sales) is a combination of all functional activities carried out after the completion of the production stage (at the end of the production process) before the direct sale of the goods to the buyer, delivery to the consumer and after-sales service [1].

Making a profit, maximizing the satisfaction of effective demand, ensuring long-term stability, competitiveness, creating a good image, achieving a certain share of turnover,

\footnotetext{
* Corresponding author: juliebeliaeva@yandex.ru
} 
gaining a given market share, determining the depth of distribution and minimizing distribution costs are the main goals of sales activities.

For stable sales of goods, you need to study the trends in demand development in your market segment and, at least, in related ones. It is also necessary to monitor the development of competitors, promote products to the market using strategies and advertising, and monitor the signals that the market gives.

The main elements of the sales policy are the following:

1. transportation of products - its physical movement from the manufacturer to the consumer;

2. product refinement - selection, sorting, assembling of the finished product, etc., which increases the degree of availability and readiness of products for consumption;

3. storage of products - organization of creation and maintenance of necessary stocks of products;

4. contacts with consumers - actions for the physical transfer of goods, placing orders, organizing payment and settlement operations, legal registration of the transfer of ownership rights to the goods, informing the consumer about the product and the company, as well as collecting information about the market [1].

Sales planning should be carried out in the following areas:

1) in a well-known market. A well-known market is orders from state-owned enterprises, military orders, and the supply of goods under long-term contracts.

2) in the free market. The main content of sales planning in the free market is the forecasting of sales of goods, the development of sales plans, the selection of the most effective sales channels, and the distribution of sales of goods in regions.

The choice of the optimal scheme of product delivery from the manufacturer to the consumer, its physical distribution, as well as after-sales service is the main content of the sales policy.

A marketing channel (distribution channel) is a person or company involved in the promotion of a product from the manufacturer to the consumer, which eliminates large gaps in time, place, and ownership that separate goods and services from those who would like to use them.

To organize an effective system of commodity distribution, the company needs to decide which channel to choose.

Types of distribution channels are:

1. direct (zero-level channel) - there is no intermediary on the way of distribution of the goods from the manufacturer to the buyer (for example, the goods are sold through the manufacturer's company store);

2. indirect - there are intermediaries in the chain of goods distribution. For example, a single-level channel is one intermediary (retail seller), a two-level channel is two intermediaries involved in the distribution of goods (wholesale and retail seller), a threelevel channel is three intermediaries (wholesale - small-wholesale - retail);

3. mixed - the use of both direct methods of selling goods by the manufacturer and intermediaries.

Distribution channels with multiple levels are used most often for the sale of consumer goods, but they are less effective. Industrial goods are often sold through a zero-level channel.

The criteria for choosing a sales channel by a firm can be presented in three factors:

1) market assessment - the size of the market, the number of buyers, their characteristics, habits and inclinations;

2) the influence of the product on the choice of the channel;

3) evaluation of the company - its size, financial capabilities, marketing. 
The advantage of using direct product distribution channels is the direct control of the enterprise over the entire sales process and direct interaction with the buyers of the product. At the same time, the use of direct channels requires more investment and a more serious management system.

A direct channel is considered advantageous if:

-the number of products sold is large, which justifies the significant costs of direct sales;

-a few consumers are located in a relatively small area, that is, the market is concentrated;

- the product requires a highly specialized service;

- sufficient number of own warehouses;

- the product is highly specialized for its intended purpose;

- frequently fluctuating price;

- the selling price is relatively higher than the cost price, which justifies the cost of direct sales.

Indirect distribution channels involve the transfer of some sales functions to intermediaries, thereby reducing the costs of the enterprise.

Depending on the number of intermediaries involved, the following distribution strategies are distinguished:

1. Intensive distribution is a sales strategy in which the company seeks to stock goods in as many outlets as possible for their greatest availability (everyday goods that allow covering a wide sales market and thereby making a profit).

2. Exclusive distribution is characterized by the sale of goods through a limited number of dealers in a certain territory.

3. Selective distribution by the number of intermediaries occupies an average position and implies the sale of goods through a limited number of retail outlets.

Sales promotion is characterized by the use of incentives and rewards that can make the consumer immediately buy the product.

Sales promotion is a short-term tool used to get the buyer to act. It should be used rarely. Endless prizes, gifts, and coupons can devalue a brand in the eyes of consumers. This may cause them to wait for the next promotion instead of buying the product immediately.

Incentive methods are the activities of a firm to disseminate information about the merits of its product and convince target consumers to buy it.

The sales promotion complex consists of four main means of influence:

1. Advertising - information that encourages the consumer to purchase a product or to act.

2. Sales promotion - short-term incentive measures to encourage the purchase or sale of goods or services.

3. Propaganda (popularization) - non-personal and non-paid promotion of demand for a product or service by spreading commercially important information about them in the print media or by presenting them on radio, television or from the stage.

4. Personal sale - an oral presentation of the product during a conversation with one or more buyers for the purpose of making a sale [2].

Various methods and programs are used to promote sales and increase customer interest:

1) Discount programs, usually used in a retail chain, allow customers to purchase goods with discounts;

2) The creation of a customer reference service can attract consumers to the organization if explanatory information is provided and the possibility of interaction during meetings is provided;

3) Personal sales encourage customers buy goods by mail at a lower price than retail;

4) Forced assortment - imposing a purchase. It is in effect when there is a long-term benefit for consumers, for example, the possibility of winning a tourist trip; 
5) Contests, competitions (lotteries, games) help attract people's attention and get them to respond to advertising and selling products by direct mail;

6) Databases. Compiling a database of desired potential buyers helps to achieve the company's marketing goals;

7) The refund method (return of a part of the price) will help to identify buyers, since buyers provide personal data (name, address) to receive a refund. This is a fairly expensive, but very effective way to get customer data;

8) Incentive systems commonly used for low-cost products may require respondents to fill in a questionnaire via direct mail;

9) Use of demonstration stands. Using displays will help increase sales or profits.

Incentive programs will help gain the loyalty of intermediaries such as dealers, distributors, small-scale merchants and sales agents.

Special attention should be paid to price incentives in the enterprise - the method most often used to promote the product.

A temporary reduction in the price of a product has its advantages and disadvantages. The disadvantage is that it does not lead to the creation of own range of customers, but encourages them to rush from one brand of goods to another, in accordance with the proposed price reduction.

The advantage is that it allows you to clearly estimate the cost of the operation in advance, quickly organize it in the simplest forms, and minimize the time of its implementation, taking into account the intended goals.

All types of sales promotion focused on the selling price of the product can be divided into three large groups:

- direct price reduction,

- distribution of coupons that give the right to purchase at a discount,

- price reduction with a delay in receiving a discount.

Direct price reduction is particularly effective:

1. at the initiative of the retail chain:

1.1. Throughout the year, there are periods when stores report the sale at very low prices of a number of selected products or a pre-set number of these products.

1.2. During specialized exhibitions and fairs, many resellers offer discounts to customers.

1.3. Retail trade enterprises post lists of products of the week (month), which combine related products of everyday demand and long-term storage products, which allows to increase the total turnover and to create a permanent clientele that will be guided by the sales promotion applied constantly.

2. at the initiative of the manufacturer. Direct price reduction, planned and organized by the company, is usually accompanied by the provision of discounts to the retail chain.

Sales promotion should be applied in exceptional cases and have clearly defined goals.

Usually, sales promotion has a multi-purpose focus. The choice of the target depends on the object of the upcoming impact. There are several types of target audiences:

1. The consumer: surely possesses the greatest value, and the whole marketing policy is reduced to the impact on him/ her. The purpose of the incentive is to increase the number of buyers and the quantity of goods purchased by the same buyer.

2. Seller: the skill and ability of the seller to market the product should not be ignored by the manufacturer. The purpose of the incentive addressed to the seller: to turn an indifferent seller to the product into a highly motivated enthusiast.

3. Reseller: is a natural link between the producer and the consumer. The purpose of the promotion is to give the product a certain image to make it easily recognizable; to increase the number of goods entering the retail network; to increase the interest of the intermediary in the active sale of a particular brand. 
Thus, a clear set of goals and the use of a set of methods to stimulate sales will allow the company to compete successfully in the modern market economy [3].

\section{References}

1. B. A. Anikin, B. A. Logistika, M. Anikin, INFRA-M, 240 (2008)

2. T. D. Maslova, S. G. Bozhuk, L. N. Kovalik, Marketing Textbook for universities: Peter, $443(2008)$

3. F. Kotler, Marketing, (Moscow: Progress, 382 (2011)

4. R. S. Igtisamov, Methodology of operational management of the company's product range based on the study of consumer preferences, Economic analysis: theory and practice, 4, 26-28 (2010)

5. A. R. Fatkullina, O. V. Kolesnikova, Organization and management of the company's sales policy, Scientific search - 7: collection of proceedings. SPb, 327-333 (2020) 